\title{
Medievalista
}

Online

26 | 2019

Número 26

\section{Johnni Langer (Org.), Dicionário de história e cultura da Era Viking}

Leandro Vilar Oliveira

\section{(2) OpenEdition}

1 Journals

\section{Edição electrónica}

URL: http://journals.openedition.org/medievalista/2722

DOI: 10.4000/medievalista.2722

ISSN: 1646-740X

\section{Editora}

Instituto de Estudos Medievais - FCSH-UNL

Edição impressa

Data de publição: 1 junho 2019

\section{Refêrencia eletrónica}

Leandro Vilar Oliveira, « Johnni Langer (Org.), Dicionário de história e cultura da Era Viking », Medievalista [Online], 26 | 2019, posto online no dia 27 julho 2019, consultado o 23 setembro 2020. URL : http:// journals.openedition.org/medievalista/2722 ; DOI : https://doi.org/10.4000/medievalista.2722

\section{(c) (7) (5)}

Mediavalista está licenciado com uma Licença Creative Commons - Atribuição-NãoComercial 4.0 Internacional. 
Título / Title: LANGER, Johnni (Org.) - Dicionário de história e cultura da Era Viking. São Paulo: Hedra, 2018 (792 pp.)

Autor(es) / Author(s): Leandro Vilar Oliveira

Afiliação institucional (Unidade de Investigação, Faculdade e Departamento, Universidade, Código Postal, Cidade, País): Centro de Educação - Programa de Pós-

Graduação em Ciências das Religiões, Universidade Federal da Paraíba, 58031-220, João Pessoa, Brasil

Email Institucional / Institutional email: vilarleandro@hotmail.com

Fonte: Medievalista [Em linha]. Direc. Bernardo Vasconcelos e Sousa. Lisboa: IEM.

Disponível em:

http://www2.fcsh.unl.pt/iem/medievalista/MEDIEVALISTA26/oliveira2611.html ISSN: 1646-740X

Data recepção do artigo / Received for publication: 1 de junho de 2018 


\section{$\sqrt[3]{20}$}

\section{Recensão / Review: LANGER, Johnni (Org.) - Dicionário de história e cultura da Era Viking. São Paulo: Hedra, 2018 (792 pp.)}

\section{Leandro Vilar Oliveira}

Os estudos sobre temas relacionados aos povos escandinavos da Idade Média, mais especificamente o que compreende o período da Era Viking (VIII-XI), vem despontando no Brasil nos últimos dez anos, sendo alavancado principalmente pelo Núcleo de Estudos Vikings e Escandinavos (NEVE), fundado em 2010 pelo prof. Dr. Johnni Langer, seu atual coordenador. Que desde então vem desenvolvendo estudos, projetos, extensões e orientações de pós-graduação sobre a temática viking e escandinava, no que resultou em livros, artigos, comunicações científicas, minicursos, cursos de extensão, dissertações de mestrado e eventos, como o Colóquio de Estudos Vikings e Escandinavos (CEVE), que ocorre anualmente desde 2012.

O presente Dicionário de história e cultura da Era Viking chega num momento oportuno e promissor para os estudos escandinavos brasileiros. Embora a historiografia brasileira registre desde o século XIX, o interesse pelos vikings, nesse mais de um século a produção acadêmica e histórica sobre eles foi bastante escassa. Antes do século XXI os livros sobre vikings comercializados no Brasil se dividiam em dois tipos: as traduções de obras acadêmicas, geralmente de origem inglesa e francesa, e obras de popularização e entretenimento, normalmente vendidas em bancas de revista ${ }^{1}$.

Todavia, dentro dessa produção não tivemos no Brasil nenhum dicionário sobre a história dos vikings. E quando partimos para Portugal, a situação não é diferente. $\mathrm{O}$ historiador Dr. Hélio Pires (membro do Instituto de Estudos Medievais) no

\footnotetext{
${ }^{1}$ LANGER, Johnni. "Uma breve historiografia dos estudos brasileiros de religião nórdica medieval". Horizonte, Belo Horizonte, v. 14, n. 43, jul./set. 2016, p. 919-923.
} 
levantamento bibliográfico feito para seu livro Os Vikings em Portugal e na Galiza ${ }^{2}$, observou que obras sobre vikings em Portugal remontam desde o século XVIII, porém, o interesse por tal tema foi pontual como ele assinala ao citar algumas obras e estudiosos nos séculos XIX e XX. Além da condição de comentar a respeito da carência de estudos lusitanos sobre esse tema. E no caso português isso é mais destacável pela condição de que expedições vikings visitaram a Lusitânia entre os séculos X ao XI, diferente do Brasil, o qual não contou com estas incursões ao seu território.

Assim como no Brasil não tínhamos anteriormente um dicionário sobre vikings, em Portugal e nos demais países lusófonos a mesma situação era observada. Porém, podese alegar que a ausência de uma obra desse tipo se deva à condição de que não haveria um mercado ou público leitor para um dicionário sobre tema tão específico, mesmo que os vikings fossem populares desde o século XIX, através das pinturas, óperas, filmes, romances, histórias em quadrinhos (banda desenhada), jogos, etc. De fato, tal argumento tem sua validade. No entanto, na atual conjuntura historiográfica, principalmente brasileira, um dicionário sobre história nórdica medieval não apenas é importante, mas necessário.

Neste caso, o novo dicionário publicado pelo NEVE, consistiu no segundo dicionário produzido pelo grupo, sendo o anterior, o Dicionário de mitologia nórdica ${ }^{3}$. A nova obra consistiu numa produção de pesquisas e diálogos com 33 colaboradores brasileiros e estrangeiros, na sua maioria formados em História, Arqueologia e Letras, além da colaboração de estudiosos do campo de Ciências da Religião e Arquitetura. Entre os colaboradores estrangeiros, membros do NEVE, temos o Dr. Hélio Pires da Universidade Nova de Lisboa (UNL), atualmente um dos principais especialistas em história da Era Viking no contexto português; o Dr. Teodoro Manrique Antón da Universidade de Castilla-La Mancha (UCLM) e o Dr. Mariano González Campo da Universidade de Valladolid (UVA), que redigiram alguns dos verbetes sobre linguagem e literatura.

\footnotetext{
2 PIRES, Hélio. Os Vikings em Portugal e na Galiza. Sintra: Zéfiro, 2017.

${ }^{3}$ OLIVEIRA, Leandro Vilar - "Recensão: LANGER, Johnni (org.) - Dicionário de mitologia nórdica: símbolos, mitos e ritos. São Paulo: Hedra, 2015 (581 pp.)”. Medievalista 22 (Julho-Dezembro 2017).
} 
Quanto aos colaboradores brasileiros, destacam-se o prof. Dr. Johnni Langer (UFPB/NEVE), principal nome da área no contexto brasileiro; o Dr. Álvaro Alfredo Bragança Júnior (UFRJ); o Dr. Guilherme Queiroz de Sousa (UFPB); o Dr. Luciano José Vianna (UPE); a Dra. Isabela Dias de Albuquerque (UFRJ); e a Dra. Luciana de Campos (NEVE). Também compõe o quadro de autores do dicionário, vários doutorandos, mestres, mestrandos, etc.

A reunião desses 33 autores resultou na elaboração de 224 verbetes, disponibilizados ao longo de 765 páginas. Além de contar com o prefácio do Dr. Neil Price, professor de Arqueologia na Universidade de Uppsala (UU), colaborador estrangeiro do NEVE e um dos grandes especialistas da atualidade em Arqueologia da Era Viking.

A introdução coube ao organizador do dicionário, o professor Johnni Langer, sendo bastante elucidativa quanto a influências, propósitos e abordagens escolhidas para a composição dessa obra. O professor Langer comenta que a inspiração do Dicionário de história e cultura da Era Viking adveio sobretudo de três obras em língua inglesa, a Encyclopedia of the Viking Age $\mathrm{A}^{4}$, organizada por John Haywood; o Historical Dictionary of the Vikings ${ }^{5}$, escrito por Katherine Holman; e o Medieval Scandinavia: An Encyclopedia ${ }^{6}$, editada por Philip Pulsiano e Kirsten Wolf.

Com base nesses três livros em específico, o professor Johnni Langer assinalou que a escrita do dicionário seguiu principalmente a orientação da nova história cultural, influenciada por escandinavistas tradicionais e contemporâneos, oriundos principalmente das áreas da História e da Arqueologia. O que repercute na escolha de temas abordados. Assim como as duas enciclopédias e o dicionário citados anteriormente, os quais abordam temas diversos que englobam personagens históricos, costumes, lugares, características da sociedade nórdica, aspectos religiosos, mitológicos, cultura literária, cultura material, etc., o Dicionário de história e cultura da Era Viking faz o mesmo.

\footnotetext{
${ }^{4}$ HAYWOOD, John - Encyclopedia of the Viking Age. London: Thames \& Hudson, 2000.

${ }^{5}$ HOLMAN, Katherine - Historical Dictionary of the Vikings. Lanham: Scarecrow Press, Inc., 2003.

${ }^{6}$ PULSIANO, Philip; WOLF, Kirsten (ed.) - Medieval Scandinavia: An Encyclopedia. London: Garland Publishing, Inc., 1993.
} 
Os 224 verbetes que o compõem são divididos nas seguintes temáticas: cultura material, aspectos sociais, história militar, costumes, fontes literárias, personagens históricos e lendários, geografia, economia, povos, literatura escandinava e a influência dos vikings na cultura pop, algo visto nos verbetes sobre cinema, literatura, artes plásticas, música e histórias em quadrinhos (banda desenhada). No caso, observa-se que as áreas temáticas da cultura material, aspectos sociais, costumes, fontes, personagens e toponímia são os em maior quantidade.

O dicionário traz uma série de verbetes abordando distintos aspectos da cultura e sociedade dos nórdicos da Era Viking, como a agricultura, a caça, a alimentação, os costumes, a higiene e saúde, a realeza, as leis, a arte da guerra, cotidiano, lazer, esportes, comércio, ofícios, ritos fúnebres, etc. Dentro desse referencial de história cultural, observou-se verbetes associados com o vestuário, o mobiliário, as habitações, a sexualidade, as mulheres, as crianças, música, literatura, além de verbetes sobre espadas, pentes, embarcações, tapeçarias, joias, produção de cerveja e hidromel. E até de temas polêmicos como a prática do estupro, do suicídio e a questão das mulheres guerreiras, tema esse bastante popular na atualidade devido a novos achados arqueológicos nos últimos anos.

No que se refere a história militar, essa se subdivide em abordar práticas relacionadas com os costumes militares, mas também suas armas e equipamentos, simbolismos, batalhas e expedições, lembrando que entre os séculos IX e XI, os vikings realizaram várias campanhas militares pela própria Escandinávia, Inglaterra, França, Portugal, Espanha e o leste europeu - algo que é complementado pelo verbete de Expansão Nórdica, e os verbetes específicos que comentam as expedições nórdicas a Alemanha, Inglaterra, França, Península Ibérica, etc., os quais nos fornecem uma visão ampla do deslocamento desses povos.

Os verbetes sobre personagens históricos e lendários apresentam informações sobre alguns vikings notórios como Érico, o Vermelho, o qual descobriu a Groenlândia e seu filho Leif Eriksson, o qual fundou o primeiro assentamento nórdico no Novo Mundo, mais especificamente na Ilha da Terra Nova (Newfoundland Isle), no atual Canadá. Além desses famosos navegantes, temos vários verbetes sobre reis como Canuto II, o 
Grande, Érico Machado Sangrento, Haroldo Cabelos Belos, Haroldo Dente-Azul, Olavo Haraldsson (Santo Olavo), Rollo da Normandia, além de personagens lendários como Ragnar Lothbrok e Lagertha.

Os verbetes a respeito da geografia são também numerosos, abarcando a maioria dos principais lugares que os vikings percorreram e visitaram durante os anos de expansão. No caso, existem verbetes abrangentes que abordam a presença nórdica na Escandinávia, na ilha de Gotland, no Mar Báltico, Inglaterra, Irlanda, Islândia, Rússia, Alemanha, França, Península Ibérica, Groenlândia, Lapônia, América do Norte, como o verbete sobre Vinland, nome dado à terra descoberta por Leif Eriksson, onde se montou um acampamento - atualmente conhecido como o sítio arqueológico de L'Anse aux Meadows, datado da primeira década do ano 1000.

Por outro lado, há verbetes geográficos que abordam temas de urbanismo, quando tratam de lugares específicos, no caso, importantes cidades como Birka, Constantinopla, Dublin, Hedeby, Helgö, Sigtuna, Jorvik (atual York), Kiev, Novgorod, Wolin, etc. Esses verbetes também complementam aspectos históricos e econômicos, pois muitas dessas cidades foram centros econômicos e manufatureiros. Assim, os verbetes sobre comércio, moedas e cunhagem, tributos e tecnologia fazem referências a alguns desses centros urbanos.

Para além de se estudar os vikings, outros povos também foram contemplados. Assim, o dicionário disponibiliza verbetes que ligam os vikings com os celtas, os francos, os godos, os anglo-saxões, os inuítes (esquimós), os sámis (lapões), os finos e os árabes. Embora não haja verbetes específicos, o dicionário também comenta o contato com os bizantinos e eslavos, entre outros povos.

No que se refere a literatura, essa é bastante abordada na obra, por se referir a várias fontes primárias. No caso, Johnni Langer comenta que a atenção dada aos anais, crônicas e sagas se deveu ao intuito de comentar a respeito desses documentos que servem como fontes históricas. Assim, aos interessados em consultar fontes escritas durante a Era Viking ou posteriormente a essa, podem ter conhecimento de fontes 
oriundas da Islândia, Noruega, Inglaterra, França e até de autores árabes, como Ibn Fadlan, o qual no século X conheceu vikings no sul da Rússia.

Todavia, o dicionário não traz nenhum verbete sobre a Edda Poética e a Edda em Prosa, as principais fontes literárias sobre a mitologia nórdica. Mas a ausência dessas significativas obras é respondida na introdução, onde Langer deixou explicado que optou em remover os verbetes sobre mitologia, religiosidade, magia, simbolismo religioso e fontes para o estudo mitológico, pois esses foram apresentados massivamente no Dicionário de Mitologia Nórdica.

Assim, para evitar repetir esse conteúdo, se fez essa escolha, ainda que o Dicionário de história e cultura da Era Vikng traga verbetes sobre alguns aspectos religiosos como ritos fúnebres, sepultamentos, o suicídio, simbolismo animal, medicina mágica e um verbete intitulado Religião e outro para Conversão ao Cristianismo. Embora que as enciclopédias e o dicionário citados anteriormente como referências tragam em seu escopo de verbetes temas sobre mitologia e religião.

Para além de se falar da literatura nórdica e sobre os nórdicos, existem verbetes que exploram a língua falada pelos vikings, o nórdico antigo (norreno), sua forma de escrever em prosa e poesia, e o uso do alfabeto rúnico. Algo que interessa muitas pessoas devido à associação das runas com a magia, a adivinhação e o esoterismo. Apesar que o foco desse verbete não seja esse, os leitores que tiverem interesse em aspectos mágicos e religiosos devem consultar o Dicionário de Mitologia Nórdica.

No que tange um debate histórico e conceitual, alguns verbetes são importantes para isso. Os verbetes Viking, Escandinávia e Era Viking debatem os conceitos dessas palavras. No caso, viking consistia em um dos vários termos usados no medievo para se referir aos nórdicos. Nesse verbete comenta-se outras nomenclaturas para tais povos, além de debater o uso romântico e nacionalista dado a essa palavra nos séculos XIX e XX. No que se refere a Escandinávia, essa região era distinta de hoje em dia, não possuindo os mesmos limites geográficos. No verbete Era Viking lê-se a explanação a respeito dessa construção historiográfica temporal, onde é apresentado como o conceito foi sendo desenvolvido desde o século XIX até ser consolidado no XX. 
Os verbetes Arqueologia da Era Viking e Patrimônio apresentam um olhar de como estudar a cultura material não apenas do âmbito histórico. Assim, são comentados aspectos metodológicos assinalando que tipos de fontes materiais normalmente são estudadas pelos arqueólogos, no que se inclui o estudo de fortalezas, assentamentos, cidades, túmulos, pedras rúnicas, objetos diversos, etc.

Complementando esses verbetes mais teóricos, destaca-se o verbete sobre Folclore, o qual, além de trazer o significado desse termo, o debate tendo como exemplo o folclore germano-escandinavo, pois no século XIX, sob uma afã pangermanista, mitos nórdicos e germânicos foram mesclados, servindo de referenciais para tradições. Outro verbete teórico é o História e Pseudo-história, no qual salienta-se percepções e os modos de se fazer história na Europa medieval - um assunto importante para se avaliar as fontes literárias daquele período, já que naquele tempo não havia uma dissociação entre história e lenda, o que torna as sagas, anais e crônicas fontes com essa dualidade presente.

À guisa de conclusão, percebemos que o Dicionário de história e cultura da Era Viking chega em momento oportuno. Primeiro devido ao aumento de estudos e pesquisas sobre o tema que vem ocorrendo nas universidades de língua portuguesa, além do aumento de interesse de um público não acadêmico, mas que motivado pela cultura pop de vikings em seriados, romances, videogames, ou até mesmo a disseminação de grupos neopagãos de matriz nórdica, vem levando as pessoas a procurarem mais a respeito, e em alguns casos, a serem mais seletivas e críticas quanto ao material que consomem. Dessa forma, um dicionário sobre a Era Viking atende aos profissionais e aos curiosos por uma leitura com embasamento científico, já que todos os verbetes trazem referências. Assim, o Dicionário de história e cultura da Era Viking consiste em mais uma das importantes produções do NEVE. 


\section{COMO CITAR ESTE ARTIGO}

\section{Referência electrónica:}

OLIVEIRA, Leandro Vilar - "LANGER, Johnni (Org.) - Dicionário de história e cultura da Era Viking. São Paulo: Hedra, 2018 (792 pp.)”. Medievalista 26 (Julho-Dezembro 2019). [Em linha] [Consultado dd.mm.aaaa]. Disponível em http://www2.fcsh.unl.pt/iem/medievalista/MEDIEVALISTA26/oliveira2611.html ISSN 1646-740X.

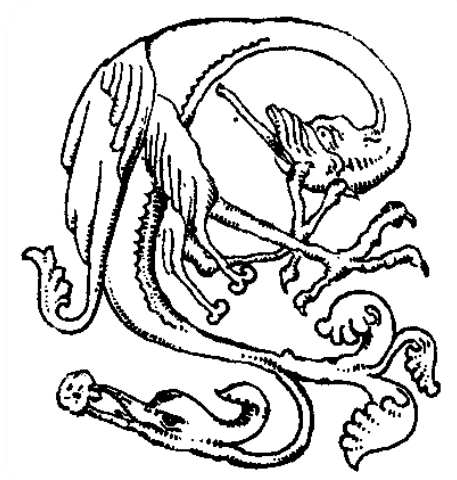

